\title{
Designing Educational Experiences: Resurrecting the Archive through Collaborative Exhibition
}

\author{
Augmented Reality, Virtual Reality and the National Library of New Zealand
}

\section{Leon Gurevitch}

University of Wellington

\section{Tim Miller}

University of Wellington

\section{Simon Fraser}

University of Wellington

\begin{abstract}
This article considers the creation of an exhibition at the National Library of New Zealand. Specifically, this project was a collaborative endeavour between the School of Design at Victoria University of Wellington and the National Library, aimed at utilising new technologies and traditional archival research to bring forgotten and rarely accessed data back to life in a public exhibition. From the outset this project sought to combine the best of both new educational technologies (augmented reality) with tactile, physical materials (created using laser cutting and 3D printing) that the public could handle and use in a way that would break down the barriers between exhibition objects and resurrected archival data. The result was an interactive exhibition focused upon the emergence of Wellington as a city and the growth of its waterfront over the last
\end{abstract}

ISSN 2560-8371

DOI: 10.24908/encounters.v20i1.13407

(C) Encounters in Theory and History of Education | 137 
century and a half. The design research project took place between November 2016 and February 2017 and resulted in a project exhibition open to the public running from May 2017 to February 2018. The principle supervisors were Leon Gurevitch and Tim Miller with a research team of three research assistants (Stefan Peacock, Alasdair Tarry and Louis Elwood-Leach).

Keywords: design education, virtual reality, augmented reality, 3D printing, archives, exhibition

\section{Concevoir des expériences éducatives: Ressusciter le concept de «l'archive» au moyen d'une exposition collaborative}

Réalité augmentée, réalité virtuelle et Bibliothèque Nationale de NouvelleZélande

\section{Résumé}

Cet article examine la création d'une exposition à la Bibliothèque nationale de Nouvelle-Zélande. Plus précisément, ce projet, qui était une collaboration entre l'École de design de l'Université Victoria de Wellington et la Bibliothèque nationale, visait à utiliser les nouvelles technologies et la recherche traditionnelle d'archives pour faire revivre dans une exposition publique des données oubliées ou rarement consultées. Dès le départ, ce projet visait à combiner le meilleur de deux nouvelles technologies éducatives: réalité augmentée et impression 3D pour créer des matériaux physiques tactiles (à l'aide de découpe au laser) que le public peut manipuler et utiliser de manière à briser les barrières entre les objets d'exposition et les données d'archives ressuscitées. Le résultat fut une exposition interactive axée sur l'émergence de Wellington en tant que ville et la croissance de son front de mer au cours du dernier siècle et demie. Le projet de recherche sur le design a eu lieu entre le 6 novembre 2016 et le 7 février 2017 et a donné lieu à une exposition de projet ouverte au public à partir de mai 2017 à février 2018. Les principaux aviseurs étaient Leon Gurevitch et Tim Miller avec une équipe de recherche de trois assistants de recherche (Stefan Peacock, Alasdair Tarry et Louis Elwood-Leach).

Mots-clés: éducation en design, réalité virtuelle, réalité augmentée, impression 3D, archives, exposition 


\section{Diseñando experiencias educativas: Resucitando el archivo a través de una exhibición colaborativa}

Realidad aumentada, realidad virtual y la Biblioteca Nacional de Nueva Zelandia

\section{Resumen}

Este artículo se concentra en la creación de una exhibición en la Biblioteca Nacional de Nueva Zelandia. Este Proyecto fue un esfuerzo colaborativo entre la Escuela de Diseño de la Universidad Victoria de Wellington y la Biblioteca Nacional con el objetivo de usar nuevas tecnologías e investigación tradicional de archivo para sacar a luz, en una exhibición pública, información olvidada y raramente consultada. Desde el inicio del proyecto bucamos combinar lo mejor de las nuevas tecnologías educacionales (realidad aumentada) con materiales físicos y tactiles (creados usando corte por laser and impresiones 3D) que el público pueda manipular y usar. Tratamos de romper las barreras entre la exhibición de objetos y los datos de archivo que fueron resucitados. El resultado fue una exhibición interactiva que enfocó en el Desarrollo de Wellington como ciudad y en el crecimiento de su espacio frente al mar durante la última centuria y media. El diseño del Proyecto de investigación tuvo lugar entre noviembre 2016 y febrero 2017 y resultó en un Proyecto de exhibición abierto al público entre mayo de 2017 y febrero de 2018. Los principals supervisores fueron Leon Gurevitch y Tim Miller con un equipo de tres asistentes de investigación (Stefan Peacock, Alasdair Tarry and Louis Elwood-Leach).

Palabras clave: diseño en educación, realidad virtual, realidad aumentada, impression 3D, archivos, exhibición

\section{Introduction}

In their 1995 book In Search of the Virtual Class Education in an Information Society, John Tiffin and Lalita Rajasingham open with the following statement:

We live in a period of transition between an industrial society and an information society. Schools as we know them are designed to prepare people for life in an industrial society. What kind of system is needed to prepare people for life in an information society? Public education systems prepare people for their place in society by emulating the factories and offices of an industrial society. Everyday, around the world, young people use bikes or buses or cars or trains to travel to school, just as later in life they will travel to work. They are expected to clock in at 
fixed times and they learn to work at desks in classrooms that are like the offices of industry and commerce. The way time is managed, subjects are segmented for study and schools are organised as bureaucracies are intimations of life after school. When the bell goes at the end of a school day, students stream out to commute home, just as factory and office workers do an hour or so later. (Tiffin and Rajasingham, 1995, p. 1)

Tiffin and Rajasingham's book is now over twenty years old (which in digital culture years, like dog years, may as well be a century). Nevertheless, the book still stands as a reference point and posits a claim made many more times across a range of disciplines in the decades since their publication: that the transition from industrial standardisation to informational individuation marks a profound change in the ways we access culture, education and media. Take, for instance, Lev Manovich's similar subsequent claim in The Language of New Media that, "Not surprisingly, modern media follows the factory logic, not only in terms of division of labor as witnessed in Hollywood film studios, animation studios or television production, but also on the level of its material organization...new media follows, or actually, runs ahead of a quite a different logic of post-industrial society - that of individual customization, rather that of mass standardization" (Manovich, 2001, p. 51). Manovich's claim here echoes Tiffin and Rajasingham's point that something fundamental has shifted in both access to information and the nature of that information's impact upon the wider world that it shapes and is shaped by. Indeed, examples abound of theorists attempting to outline the geography of a post-industrial information age. Henry Jenkins, for instance, notes that in an age of information abundance, the nature of academic endeavour inevitably changes as more and more non-professional theorists outside the traditional academic realm begin to lay claim to information previously beyond their reach (Jenkins, 2000). In most cases the argument is similar: that emergent information technologies are in the process of radically changing the nature of, access to and consumption of, information. By and large this has played out and continues to play out; though as is often the case with technological revolutions, the scale and scope of the shift is taking longer to manifest than early hyperbole would suggest. Certainly, the significance of the information age and its abundance of data has been apparent for quite some time. In his entry on Data Visualisation in the book Software: A Lexicon, Richard Wright points out that increasing quantities of data were identified as a problem to be managed from the late 1980s "as the increasing power of computing and the decreasing cost of digital storage created a surge in the amount and complexity of data needing to be managed, processed, and understood." (Wright, in Fuller, 2008, p. 78). Wright points out that the US National Science Foundation published a report titled "Visualization in Scientific Computing" in 1987 "that warned about the "firehose of data' that was resulting from computational experiments and electronic sensing" (Wright, in Fuller, p. 78). If anything, this "firehose" of data has turned into a raging 
torrent in the intervening three decades, and even while the opportunities and methods for interpreting this data have grown seemingly exponentially ${ }^{1}$, the question of how to adequately deal with the surplus of data has only become more pressing.

Debates over data and its management have, however, also matured in that time, expanding their focus beyond simply that of whether and how to adequately quantify, manage and visualise it to a more nuanced set of questions around what kind of data to extract from the endless river (or torrent if we are to maintain the earlier metaphor) that now flows. More specifically for our own work, questions have shifted in the last decade from ones that ask how information will change the nature of media consumption, education and cultural production, to questions regarding the kinds of information available, the project of deciding what information to attend to, how to engage with such information, and precisely how to approach the task of resurrecting such data. While in the late 1980s the task of data-visualisation was an apparently relatively straightforward question (though by no means easy task) of transforming data in a database into visuals on a screen, in the contemporary context the form that such "visualisation" can take has rapidly multiplied, as have the sources of data, both contemporary and historical, as the task of digitising the archives of the past have continued apace.

Just as access to information has changed the way non-academics can lay claim to knowledge and the act of theorising, information technologies and their impact in reshaping the physical and practical world are also changing the way professional academics can lay claim to the act of making and doing. 3D printers, C\&C routers, VR headsets, mobile platforms, robotics and computational capacity have all seen development curve of increasing abundance and decreasing cost over the last decade to the point where we are starting to see such proliferating technologies begin to shape the nature of cross disciplinary research projects. With all of this in mind we wish to describe in this article a specific intervention made in the realm of public education and access to information in the form of a year-long design research project between the School of Design in Wellington New Zealand and the National Library of New Zealand. In this project we accessed the National Libraries archives with the expressed aims of identifying novel data generally lost to the public eye that could be mined, processed and exhibited as a public exhibition. More specifically, we aimed to access data regarding the growth and development of Wellington over its 200-year history as a port city and use immersive and interactive technologies to bring long dormant information back to life. Crucially, this research project sought to bring long forgotten data to life in such a way that it could be manifest in the physical world and the digital world simultaneously. Importantly, we sought from the very beginning of this project to break down the often clumsy distinction between "physical" and the "digital" in order that the data we extracted from the archives could have a more tangible and impactful educational value, at the same time as it might also be engaging and entertaining to exhibition users. 
Of course, defining the parameters of impactful educational value is no easy feat (as several millennia of pedagogues would no doubt attest). In this case, and to narrow it down to the specific literature on learning in a museum context, we turned to George Hein's work on the constructivist museum. Chiefly, Hein outlined a number of questions that exhibition designers should ask themselves when constructing an exhibit: "What is done to acknowledge that knowledge is constructed in the mind of the learner? How is learning itself made active? What is done to engage the visitor? How is the situation designed to make it accessible-physically, socially, and intellectually - to the visitor?" (Hein, 1998, p.156). In response to these questions the team considered it vital from the earliest stages of design to create an exhibit that allowed multiple entry points into the data visualisation: a means of allowing visitors from a wide range of backgrounds to not simply engage with visualisation data on a narrow pathway of interaction but to play with the data in as broad a manner as possible. For this we decided upon multiple systems of layers data in both digital and physical format.

Our original aim was to produce a VR experience of Wellington's shore front and the development of it over time. While we created Wellington's city centre and shore front virtually, in the end augmented reality became a much more powerful tool in the process of revealing and engaging the viewing public where the data was concerned. In order to consider the project in depth, however, I wish to first consider academic perspectives on the history of exhibitions and their design as educational experiences before going on to outline our own project and its implications both for design research and for education and exhibition in the contemporary context. Our aim in addressing the history of exhibitions is to tease out the aspects of AR, VR and physical exhibition with a specific aim in mind: there is a danger in the contemporary context that discussion of immersive technologies becomes a fetishisation of the technology rather than a recognition of its current and future potential via an understanding of its relationship to exhibition practices that long predate such technologies. The best way to appreciate VR and AR's educational potential is to move beyond the specifics of the technological achievements and the peculiarities of the technological sublime and the best antidote for this is to understand the history of what went before so far as educational exhibition design is concerned. In her book on visual technologies and exhibition contexts Shivers Down Your Spine, Alison Griffiths argues persuasively that the concept of immersion and immersive modes of interaction are not new, rather that they have simply not received enough scholarly attention:

less scholarly attention has been devoted to the immersive and interactive modes of spectating peculiar to nineteenth-century science museums.... For this very reason it is vital that we trace debates around ideas of immersion and interactivity to an earlier era in museum history in order to deflate some of the grandiose claims about new media and to ground the discourse historically rather than purely 
theoretically. So much of what passes for "new modes of immersive and interactive" spectating has precedents in the nineteenth century; it is not just shortsighted but extremely egocentric of us to assume that late capitalism (whenever that is) and postmodernity alone lay claim to these ideas. (Griffiths, 2008, p. 160)

Griffiths is right here. Indeed, one could argue, as Griffiths does, that museum exhibitions, by virtue of their layouts and structure, have long been interactive media in their own right. Of course there have been varying degrees of tactility with precious objects encouraged and discouraged at various times, but simply the fact of their existence, as spaces one walks through, around which objects are placed and within which spectators engage, has meant that they have had various levels of interactivity and immersion built into them. But the fact that museum exhibits have long been interactive in nature has not precluded problematic dynamics regarding the accepted wisdom over interpretation of the objects. As Eilean Hooper-Greenhill has argued:

Objects in museums are subject to curatorial procedures of registration, documentation, and classification which have, in the main, resulted in their allocation to a fixed physical and conceptual position within the collections, which in turn has tended to generate a fixed meaning. This single fixed meaning, almost always relating to an academic discipline (art history, or archaeology for example), has seemed the correct and only way in which the object should be interpreted. (Hooper-Greenhill, 2000, pp 124-125)

With this in mind our team was also aware of the danger of not using history as a guide to avoid past mistakes when it comes to education in spaces of cultural and institutional value. To suggest that the AR and VR experience is wholly new could be to risk ignoring lessons learned via the interactive media of exhibitions in the past. This is all the more important in a post-colonial context of a country like New Zealand in which Wellington (previously Port Nicholson - literally transliterated in Maori as Pōneke - and before that in Maori, Whanganui-a-Tara translated to the great harbour of Tara) very specifically functioned as a key conduit in a process of colonisation. The profound differences of approach to objects, spaces and places is again perhaps best articulated by Hooper-Greenhill (2000, pp. 49-75) in her description of a Hinemihi (Maori meeting house) blessing ceremony in England in 1995. Hooper-Greenhill paints a stark contrast between the national trust officers who described the Hinemihi and its contents as "works of art" to be looked after in their care while Hare Waikingi, the Maori elder referred instead to it as if "she" were a living person. As for a Hinemihi, so for the land of New Zealand itself. In representing the changing nature of the Wellington waterfront over time our team did not want to present it simply as an inanimate space in which was "developed" by an incoming colonial authority. Instead, 
the exhibition had to represent a Wellington's waterfront as and undergoing continual growth and change.

In the New Zealand context, any exhibition on the development of a port city like Wellington, based in a city like Wellington, must at the very least be careful not to replicate the kind of colonial discourses that were prevalent in the categorisation of Britain's colonies of the late eighteenth and early nineteenth centuries. But more importantly, in recent years exhibitions in an Australasian context have had to move further than simply a post-colonial national re-imagining of years past. In her excellent book Colonial Photography, Anne Maxwell argues that:

Exhibitions erected in the colonies were initially modelled after those in Europe, but the drive towards independence made modifications inevitable. By the 1890s Europeans who settled in Australasia had many attributes in common with the citizens of North America. They were mostly people of British stock who had migrated to resource-rich, reputedly 'un-developed' lands occupied by indigenous populations. They shared the vision of a New World society moulding itself on the purer spirit of the pioneer, a society based on capitalism and meritocratic democracy, free of the Old World's legacy of inherited privilege. Moreover, they were intent on fashioning a strong national self-image to counter the image of dependency and inferiority foisted on them by Britain. (Maxwell, 2000, p. 5)

This need to counter an image of dependency and inferiority has diminished over the post-war decades as New Zealand has turned its face slowly toward its place in the Asia Pacific as a Pacific Island nation. This is not to say there are not a whole host of problematic post-colonial legacies still on going, but it is also no longer the limited imperial space that it once was. The centrality of New Zealand's indigenous culture is slowly emerging from this ongoing shift and it is notable, for instance, that the national museum of New Zealand no longer bears such a title. Instead, the Te Papa Museum (literally just referred to as Te Papa) is so named for its explicit meaning in Te Reo (Maori language): "our place."

\section{Research and Development of Augmented Reality Exhibition}

While Griffiths is right to argue that the notion of interactivity as a contemporary technologically facilitated phenomenon is a fallacy, it is also true that emergent forms of VR and AR offer new and novel ways to invigorate previously static and often untouchable exhibition content held behind glass. As we saw earlier, the "firehose" of data identified in the 1980s has only grown rapidly and continually. However, in the rush to capture, extract and curate content from this growing data torrent, there is also the risk that historical forms of data, as yet undigitised, or digitised but left behind in the rush to new information and forms of big data, are ignored or lost in the geography 
of data abundance. To this end, this risk and these challenges are increasingly recognised by institutions and organisations who specialise in the collection, curation and exhibition of historic information. Equally, institutions are also increasingly aware that they are sitting on a goldmine of historical data that is limited in quantity but rich in potential value and the insight it can offer.

In this context, Victoria University of Wellington's School of Design were approached by Public Programmes of the National Library of New Zealand and, following discussion, the opportunities for the application of future digital technologies were explored by a research team of five Social, Digital and Industrial Design specialists. The initial deep dive into the National Library Collection was performed in a ten-week period from November 2015 to February 2016 with the team considering the potential for digital and physical outputs encompassing digital manufacturing, computer software and visualisation techniques. The aim of this process was to demonstrate through prototype exhibition outcomes that could resurrect archival data long dormant for public consumption that would have both informative, educational and entertaining value in revealing aspects of Wellington's historical development that may have been forgotten.

Initial investigations into applications of potential digital technologies that diminished the distance between historical, document-based data and the needs of contemporary physical exhibitions yielded some fascinating possibilities. Examples our team took as indicative models included an augmented reality display of the 2016 Lego Catalogue; an installation of Netherland's industrial timeline visualised as kinetic windmills when viewed through the camera and screen of a smartphone or tablet and Google Binoculars that placed a virtual reality headset into an environment offering the immersive experience of another environment in the process. Besides corporate projects, however, there are numerous examples of artists and designers such as Adrienne Segal and Eddie Opara working in the field of digital data sculpture. Segal's project on California Water Rights (2017) in particular was something our team considered closely, as was Opara's Interactive Table at the SCAD Museum of Art (2012). The point here was to understand what had already been done and by doing so to understand what technologies were currently yielding successful results in engaging users in the physical and virtual crossroads of data exhibition. The 2016 Lego Catalogue installation was a fusion of kinetic and interactive models with moving image. By contrast, the Google Binoculars exhibit placed a virtual reality headset within the housing of a classic coin operated binocular stand. The VR headset contained a 360-degree view of a location different to their surrounding environment (for example, Shackleton's Hut, Antarctica within Sydney Harbour). The stand was placed in an environment where unsuspecting users could experience entirely different worlds intuitively. The installation was intelligent in its approach to deconstructing the presumed immersive nature of virtual reality. Importantly, the mobility of the google binoculars exhibit enabled interaction within an urban environment and outside its 
usual context: something which made for increased engagement and broader educational possibilities via a clever combination of manipulated physical prop, smart use of physical environment and virtual reality technologies not usually associated with the mundane urban technologies of the past (in this case traditional coin-operated urban binoculars). Segal and Opara's works were of more interest to the group so far as the public exhibition of public data was concerned. Segal's work on physicalising data regarding water rights especially had close cross overs with our own approach to a changing historical waterline and its uses.

With this assessment undertaken the research team concluded that the combination of physical components with digital components in a single installation established a more engaging experience, mindful of the fact that the digital spectrum remains a foreign concept to some users in the context of public installations. It was decided that when digital information is contextualised through physical or interactive models and environments, the exhibitions stood more of a chance of fulfilling our aim of operating as intuitive, engaging and relational gateways to historical data. There was another side to this thinking too: all too often in the history of education and exhibition, new technologies have been fetishized as inherently utopian in their educational potential to engage. With that in mind our research and design team concluded that a robust and simple technological interface that brought digital and/or digitized data into play in the physical exhibition context stood the best chance of engaging the public whilst offering novel educational experiences at the same time in a way that was not about the fetishization of technology for its own sake.

\section{Resurrecting the Archive: Source Material for an Educational Exhibition}

National Library of New Zealand maintains an impressively comprehensive collection of historical records specific to New Zealand and Wellington consisting of a wide array of media from hand drawn art, photography, building plans, maps, newspaper articles, recorded audio and physical artefacts. Our team was provided unrestricted access to the Collection and encouraged to extract content deemed most suitable for digitisation and application in our chosen exhibition formats and technologies. To cope with the scale of information available the team pursued research avenues within wide but predetermined topics. ${ }^{2}$ These topics then yielded statistical data and articles spanning New Zealand's entire settlement history. With the National Library of New Zealand headquartered in Wellington, and the exhibition due to take place there, our team chose to prototype exhibition scenarios relevant to Wellington's recorded history. The scenarios were grouped according to four themes (The hidden city; the growth of the city; the historical city; the alternate city) with the research team identifying a particular research interest remained constant across all four: Queen's Wharf. 
Queen's Wharf, Wellington is not primarily defined by its historic interest. It is a symbol of familiarity, controversy and identity at a local and national scale. It was also a site of colonisation. This wharf was the site through which the lower North Island was connected geographically, economically and militarily to the networks of the then British Empire. Wellington's waterfront reclamation was a typical exercise of Victorian Engineering executed by The New Zealand Company upon the early British settlers arriving into Wellington City and in the process Maori rivers and landmarks were lost beneath an industrial infrastructure that sought to overcome the undulating terrain presented challenges to incoming colonists efforts to settle and provide an entry and extraction point for the lower North Island. From this point of view, Queens Wharf was a fitting focal point for the rapid changes that took place over a relatively short historical period of time in the emergence of Wellington. The reclamation initiative sought extensive earthworks that would transform a considerable body of water from what was then known as Port Nicholson, into level, buildable and subsequently saleable land. The project spanned just over one hundred years, with the Queen's Wharf precinct subject to substantial modifications over three stages, 1857-1867, 1889-1903 and 1967-1970. Queen's Wharf was a centrepiece to the reclamation throughout the entire period, therefore became a symbolic constant in the process.

For the initial project, our team built a prototype historic virtual environment of Wellington's waterfront (see image 1) for use in a VR headset located within a binocular style viewer placed on the waterfront. When looking through the binoculars, viewers would see a recreation of Wellingtons waterfront as it would have looked one hundred years earlier from that location. This, it was envisaged, could act as a form of publicity for the central exhibition as the National Library itself. While initial tests of the waterfront VR were promising, in the end the team opted to place time and focus on the Library exhibit itself on the basis that a more comprehensive exhibition at the library would have greater educational value and exhibition impact. 


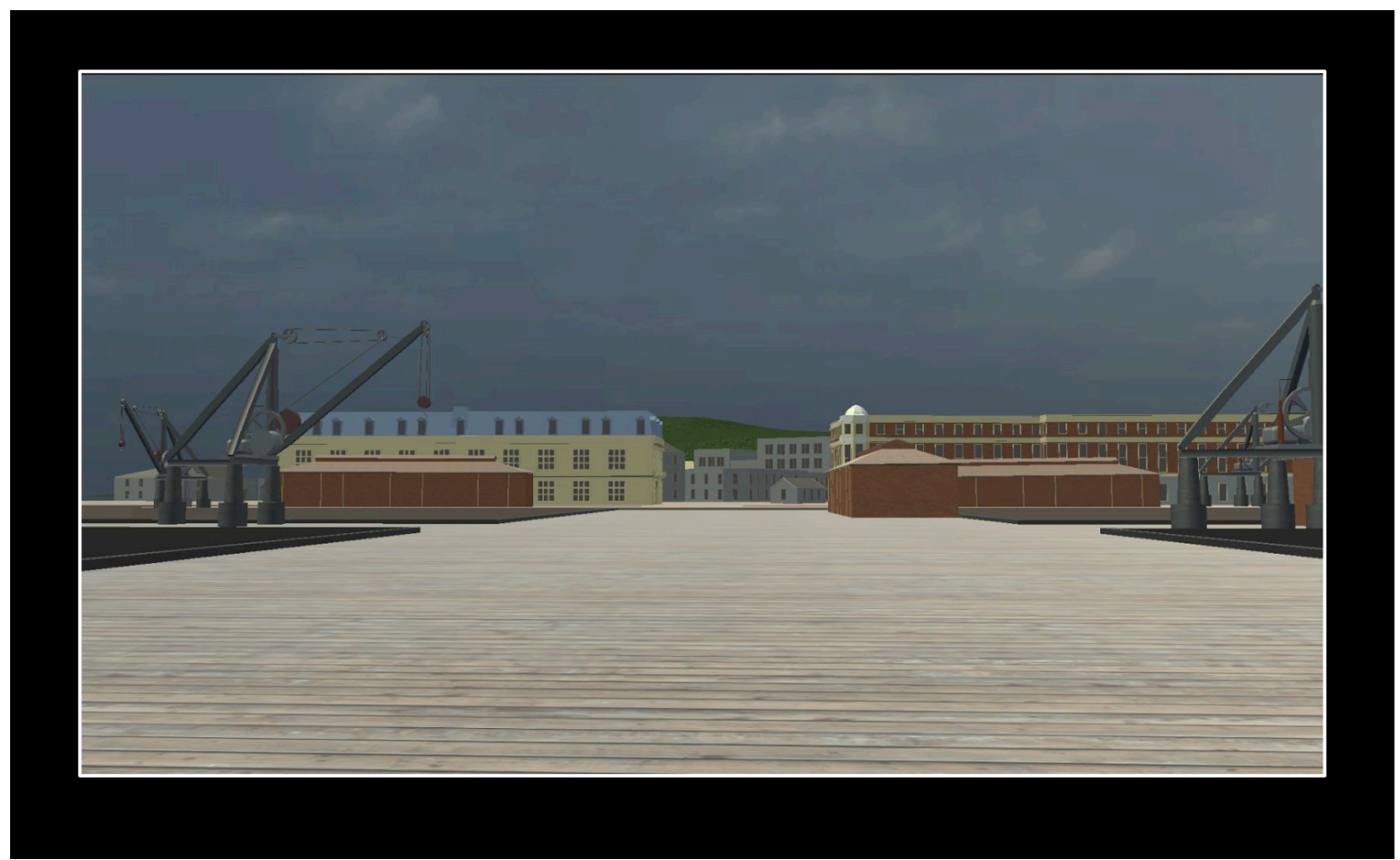

Image 1: Early Stage Prototype of Wellingtons Historical Harbour

Once we had settled upon the exhibition itself, the next question revolved around what kinds of resurrected data we would utilise and how we would make that data both tactile and interactive. Our initial exploration led us to try quick prototypes of 3D printed buildings from Wellington's past. 3D printing presented us with a fascinating way to quickly and easily resurrect architectural plans of buildings that were lost in the generational process of urban renewal (especially in an earthquake prone city like Wellington). Here the team's process of resurrecting physical urban objects long since destroyed but preserved as archival data reminded us of Laura Mark's assertion in her book Touch (2002), that, "Materiality is mortality. Symbolization, or the abstraction of communication into information, is an attempt to hold mortality at bay" (Marks, 2002, p. xi). We are tempted to go further here however, for while the data in the archive held the absolute death of Wellington's historical urban environment at bay, its location in a rarely accessed archive merely constituted a kind of life support. By 3D printing these buildings and making them accessible to the public we may have constructed a materially mortal exhibition (it did after all have an end date) but at least the objects could live again in a tactile form. 


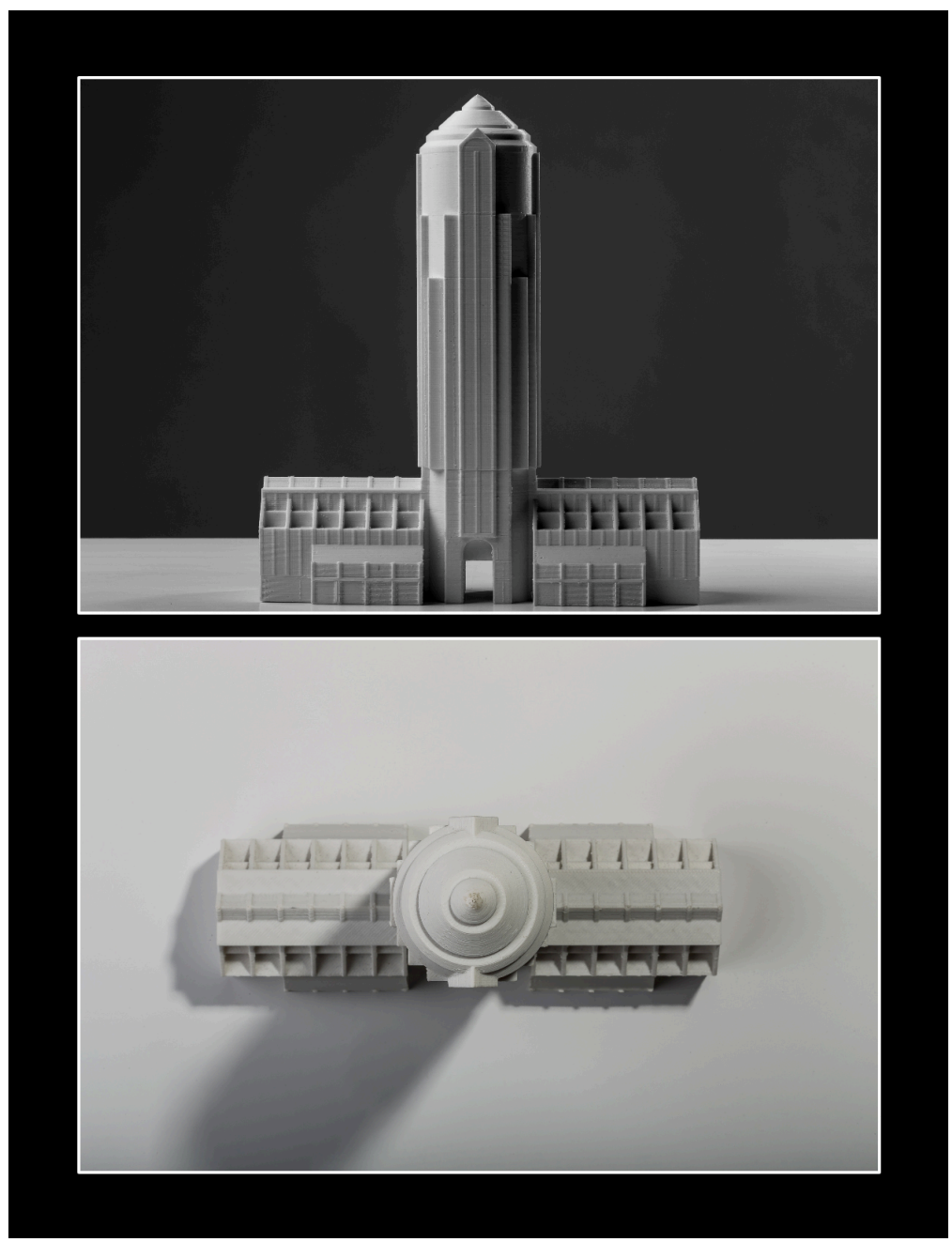

Image 2: 3D Print of Lambton Tower Building Proposal

Perhaps because of this, by far the most interesting type of buildings that the team settled on recreating were not buildings that had once stood and since been demolished but were instead proposed buildings that had never been built and never would be built. As, for instance, with the proposed Lambton Tower development the team found, the question of these proposed buildings mortality became all the more interesting because they had never really been born in the first place. The capacity for the archive to offer up data and plans that could allow for a reconsideration (many years after the fact) of plans and ideas that never made it out of the proposal stage and which, as a result, had little public engagement at the time of its conception became something of a minor obsession for our team. What is more, there was so much of this material to choose from that we found ourselves spoilt for choice on what to select for exhibition. In the end, we opted for a strategy of choosing buildings that, had they been built, would have been both spectacular and historic mistakes. The Lambton Tower, for instance, stuck out to us as both ugly and unnecessarily in shape and scale for the Wellington waterfront. The contemporary waterfront has been developed into a 
hugely popular and vital pedestrian and community corridor supporting thousands of commuters every day. Had the rather phallic looking Lambton Tower been built, it is difficult to see how the development of this corridor would have been possible, and even if it had, the character of the Wellington waterline would have been significantly disrupted. In the field of public architecture there is often such a focus on the controversial works that do get built but should not have been, or otherwise the missed opportunities of masterpiece proposals that were put forward but failed to be realised, that we felt it would be much more interesting to bring to life the monstrosities that Wellington was lucky enough to narrowly escape. We began to realise that there was a potentially limitless quantity of material from the past (and potential conversations with those pasts) that, coupled with new visualisation and fabrication technologies, could allow us to resurrect forgotten public and private discourses which allowed for a tactile haptic engagement that 2D plans would simply not accommodate. Fittingly given our earlier consideration of the colonial origins of Wellington's waterfront development, the term "haptic" and its relationship to environmental space bears consideration here:

The term haptic emerges in Deleuze and Guattari's description of "smooth space," a space that must be moved through by constant reference to the immediate environment, as when navigating an expanse of snow or sand. Close-range spaces are navigated not through reference to the abstractions of maps or compasses, but by haptic perception, which attends to their particularity. Inuit and other nomadic people are Deleuze and Guattari's privileged agents of haptic perception. (Marks, 2002, p. xii)

Here, then, a case can be made that the act of materialising colonial archival material regarding the urban development of space is more than a question of the attempted immortality of data versus the mortality of the material: it is also a question of returning these abstracted maps back into an object form that provides a haptic engagement with the urban environment that was lost amid the often brutal process of colonial engineering.

Returning to the resurrected 3D printed buildings, however, as fascinating as these plans were, they lacked in a level of contextual interactivity required for our project to have the creative engagement and educational value we desired. With that in mind we decided to turn to the idea of puzzles whilst including both physical 3D objects and at the same time the potential for virtual reality technologies in the form of augmented reality to play an additional role as a third layer.

Following this decision, the question that arose for our design research team was less driven by the data uncovered and more a pedagogical question of exhibition design. Specifically, our aim was to provide a level of interactivity less often associated with a National Library that would allow for a proactive engagement with the material we were uncovering but which would not sacrifice meaning in the name of an imagined 
"interactivity for interactivities sake". To achieve this we had to answer a seemingly simple question that was anything but: what kind of interactivity were we seeking? To answer this Griffith's articulation of the nature of "interactivity" and its construction as a concept over time was again useful here:

What has changed is the discursive construction of the term interactivity, which over time has come to mean a lot more than simply touching an object or manipulating an exhibit to affect an outcome. Conceiving of interactivity within a broader intellectual frame becomes prominent within museum writing beginning in the 1950s; for example, Guggenheim Museum director James Johnson Sweeney drew an analogy between a museum exhibit and a book to make his point about the integration of the senses in museum design; the only major difference in visiting an exhibit, he argued, was that "the visitor actually moves through the exhibition and becomes part of the installation... But each speaks primarily to the sense of the observer, and each in the end, to have its effect, must be assimilated or digested intellectually." Today, at least in the world of museum education, interactivitypremised upon a constructivist (learn by doing) versus a behaviorist/didactic (learn by being taught) model of learning-connotes agency, a more dialogic model of visitor-centered learning, and some awareness of what Ivan Karp and Steven D. Lavine famously called "the poetics and politics of museum display." (Griffiths, 2008, p. 162)

Here the book-based analogy was particularly apt given the location and conception of our exhibition within a National Library in search for a means of opening its archive to the public in general and to age ranges (particularly the very young) not historically targeted as its typical audience. Our design challenge, then, became a question of precisely how we could and would translate the data and narratives that were emerging from a predominantly textual archive into an explicitly constructivist form of interactivity in which young users could learn by doing. In other words, the technological interactivity had to be robust and to take second place in favour of an approach of learning by doing that placed access to the data mined first.

Productively for our team, the exhibition was to fit within a wider, and in some senses more traditional, exhibition of topographical archival data (see Image 2). Here, archival maps of Wellington and New Zealand were already on display and arranged in a traditional sense: mounted on the wall and held under protective Perspex. 


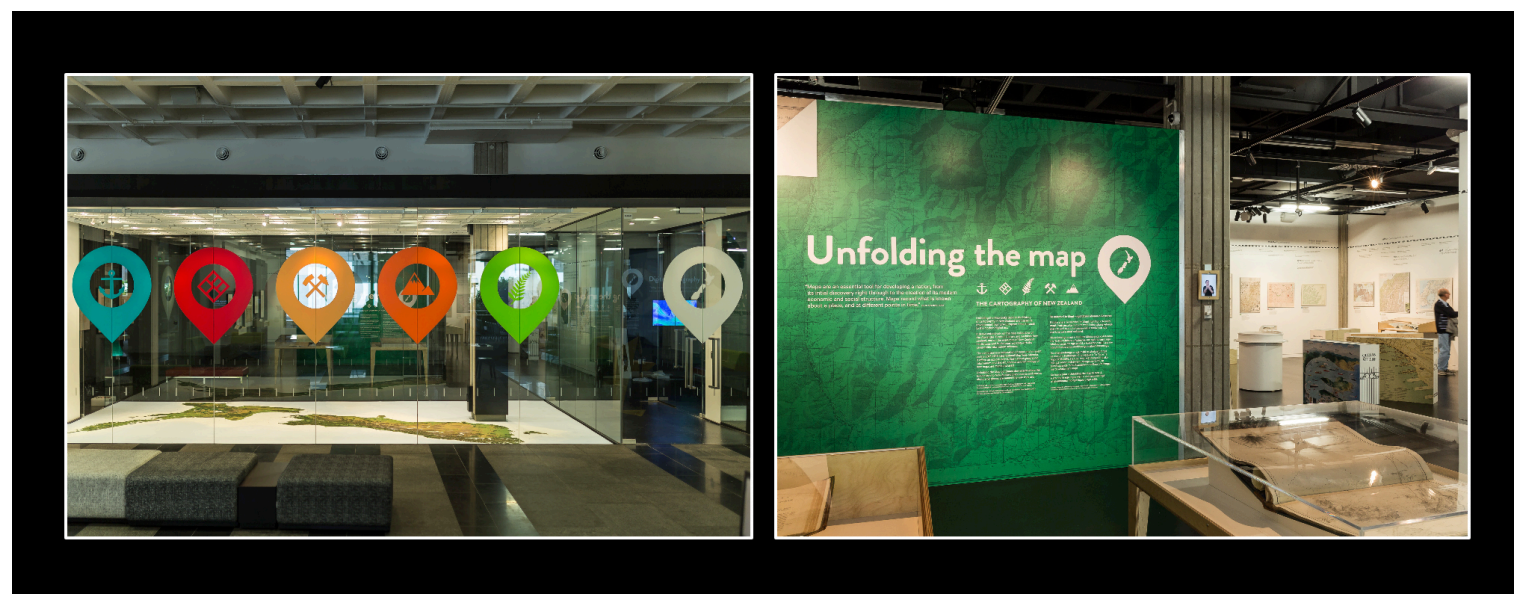

Image 3: National Library of New Zealand's "Unfolding the Map" Exhibition

\section{Designing an Educational Experience}

Into this mix we envisioned an exhibition that used the principle of the puzzle to engage visitors with the process of Wellington's development. The exhibition architecture for this that we settled on was a wheel model of exhibit plinths as "spokes" that contained information regarding the emergence of Wellington's waterfront leading to a central focus in the main "hub" at the centre (see image 3). The "spokes" not only contained information on Wellington's developing waterfront, however, this information took the form of movable map pieces that could be removed from their placements on the plinths and progressively placed on the central hub to build up a variable composite of Wellington's waterfront as it developed over time. Crucially, we then added a third layer to the exhibit by providing the optional extra of a virtual model of the buildings on the waterfront as they built up over time. This model was specifically physically linked to the movable map pieces and viewed through a tablet in the form of an augmented reality layer. The advantage of this was that different levels of architectural urban complexity could be accessed via the specific map pieces of waterfront development laid down, providing for a rich and complex interaction between the data extracted from the archive and the map of development in both physical and digital form. Importantly, the exhibit did not require augmented reality for meaning to be made and taken from the exhibition pieces provided. A visitor could literally move round the exhibition and look but not touch in the traditional way museum displays often required. For the more adventurous, map pieces could be picked up, moved around and the puzzle of Wellington's complex chronological development solved. Finally, for those wishing to access the digital data that had emerged from the project, the augmented reality app allowed for a third form of interactivity that even included a dense layer of historical information on specific buildings should the user wish to engage with it. In this way our team were able to 
build up and provide the viewer with multiple layers of interactivity which could be progressively accessed but which did not have to be if the viewer did not wish to engage any further. To return to the question we asked ourselves earlier in the process, "what kind of interactivity do we want?" we were able to eventuate an outcome that was as close to "all kinds of interactivity" as we could get whilst not requiring the visitor to undertake any more engagement than they wanted.

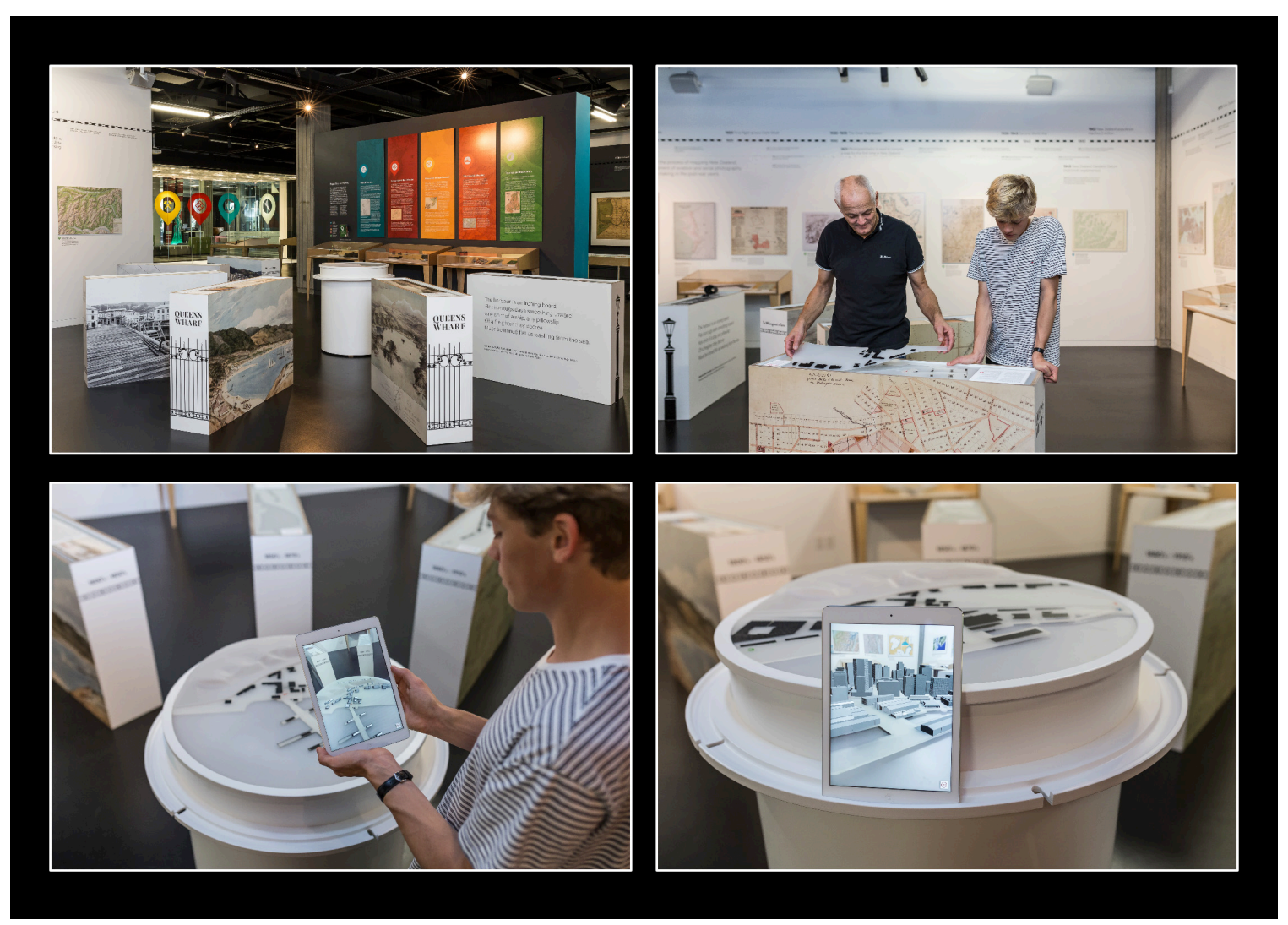

Image 4: Final Mixed Media Exhibition Set Up

Turning to the exhibit and AR interface itself, the team's initial task was to create a physical interactive reclamation puzzle that was symbolic and intuitive. We settled upon the idea of a puzzle because it was a simplistic yet effective method of demonstrating that the land was reclaimed throughout different time periods. It encouraged user interaction and allowed direct comparisons of before and after through the addition and subtraction of pieces. It also allowed for an excellent physical bridge between the digital data and the way that data could be viewed and understood as a result of the manipulation of physical markers that were informative in and of themselves. Early in the design process our team sought to look beyond the idea of a "physical" versus a "digital" information space. For one thing, the manufacture of the physical installation utilised a wide array of digital manufacturing processes. The 3D digital topography of Wellington's shoreline was generated within digital software then 
CNC milled from timber. This produced a mould which enabled an acrylic sheet to be vacuum formed (heated suction moulding) into the same shape. This process ensured the materiality was consistent throughout the various components. A large circle, representative of the water, was laser cut from acrylic to ensure a durable surface to support the reclamation pieces. The reclamation puzzle pieces were also laser cut via computer control, and their profiles determined by extracting vector data from the Library collection content. Finally, a cylindrical housing was machined out of engineered timber to complete the physical model.

From the initial design process through to the final exhibition piece, then, physical outputs and digital data were fundamentally intertwined in a way that made the distinction between the two questionable beyond an understanding of final user interaction experience. One of the consequences of this, unfortunately, was that the AR app we developed had to function specifically within the space of the exhibition itself. We considered making an app publicly available to visitors who wanted to download it to their phones, but we felt there were a number of drawbacks to this strategy that outweighed the advantages of an app on visitors' personal devices. First and foremost, the screen size of mobile phones, whilst much larger than a few years ago, are still not large enough to provide what we considered to be a suitable interactive experience of the augmented reality functions we had created. On that basis, and on the basis that few visitors would be arriving with larger, more suitable tablets, we created an app that was installed on tablets located with the physical exhibition itself. We were, however, able to leave the tablets untethered so that visitors were free to walk them around the entirety of the exhibit itself. For future development we discussed an app for phones, but we agreed that for this to work there would have to be significant extra material around the waterfront itself. Ultimately, here we had to trade a degree of accessibility and ownership over the layers of data for usability and user experience in the immediacy of the exhibition itself.

With this in mind, the digital model for augmented reality overlay was undertaken simultaneously. The approach was to digitally model Wellington's building infrastructure throughout the three periods of reclamation. Images from the Collection were categorised into their corresponding time periods, 1857-1867, 1889-1903 and 1967-1970 respectively. The images were subsequently used for their visual information of which informed the 3D digital model. ${ }^{3}$ Augmented reality functions by recognising geometry in the physical environment and orienting the digital model on the digital screen accordingly. Therefore, distinct markings were etched onto the reclamation puzzle pieces. What resulted as each piece was laid onto the physical model was a digital model of the buildings corresponding to that time period updated on the digital display. 


\section{Final Observations on the Educational Value of a Mixed Media Exhibition}

We set out to create an exhibition that could achieve multiple aims at the same time: 1 . to rematerialize data long dormant in the archives. 2. To make sure that in exhibiting this material we did not repeat past mistakes of colonial Eurocentric constructions of space and place as inanimate objects. 3. to offer an exhibit in which the data and the physical and digital visualisations were accessible on multiple levels of engagement and ownership by the visitors. As Helen Tiffin has argued in her account of postcolonial literatures and counter discourse, "the rereading and rewriting of the European historical and fictional record are vital and inescapable tasks. These subversive manoeuvres, rather than the construction or reconstruction of the essentially national or regional, are what is characteristic of post-colonial texts" (Tiffin, 1995, p. 95). To what extent were we successful at this remains for others to judge, but as a design team we attempted to place an approach to Wellington's historical development that did not merely replicate colonial approaches to space as inanimate object form.

One of the difficulties in writing this paper has perhaps been best summarised by Marks when she aptly states:

When translating from one medium to another, specifically from the relatively more sensuous audiovisual media to the relatively more symbolic medium of words, the task is to make the dry words retain a trace of the wetness of the encounter. (Marks, 2002, p. X)

Indeed, when describing the research, development and construction of an exhibition we have only described half of the encounters: those between the archive and the design team, between the data and the fabrication tools, between the design team and the exhibition that resulted. These were all "wet" encounters, as Marks puts it, that are difficult to summarise in the dryness of an academic article. And they do not even touch upon the many thousands of encounters that took place once our exhibition was in place and accessible to the public. It was, however, a real joy to witness the kinds of public interactions that took place and left us thinking about how such processes could be encouraged further so that dialogues between often long forgotten archival data and the general public could take place with greater frequency and to greater effect. Importantly, our claim here is not that the educational value of our exhibition was in making publicly displayed data interactive, as Griffiths points out, there is a long history of this going back to the nineteenth century:

Stagecraft, technology, display, education, and enlightenment were mutually informing discourses in the nineteenth century, and just as the lecture theatre or music hall was transformed into "an immersive environment, creating a sensory, 
interactive interface between audience and the visual effects of science," so too was the mechanical exhibit changed by being set into motion. (Griffiths, 2008, p. 164)

Rather, the significance of this research and exhibition project for us was in the practical experience of translating archival data into usable exhibition material and crucially, the increasing ease with which that is a possibility. Herein lies the significant potential crossover between design, education and exhibition. The tool sets were now have are translating into quicker and easier extraction, reinterpretation and materialisation of data that would previously sit unused in the archive. Where archives have been used in previous exhibitions, this has been done as the result of large professional teams of curators deploying a significant budget. For our team, the revelation of this project was the realisation that analogue and semi-digitised archives are a treasure trove of potential material and the emergence of industrial and digital design tools and processes are only expediting the educational possibilities that flow from them.

\section{Acknowledgements}

This project was led by Leon Gurevitch and Tim Miller at the School of Design at Victoria University of Wellington. But our team had a core set of research assistants followed by an even broader set of experts and institutions without whom this work could not have been completed. Simon Fraser kickstarted the project with his everpresent and seemingly endless capacity to initiate external research collaborations across institutions and industry. Our core team were Stefan Peacock, Alasdair Tarry and Louis Elwood-Leach. Outside Victoria University of Wellington, the National Library of New Zealand and a whole host of staff both in upper management and across the archival team were central to the success of this project and their valuable contribution to this project cannot be overstated. Last but by no means least Liane McGee from the Design Consultancy FortyFive produced publicly facing graphic content for the exhibition. This research was co-funded by the National Library of New Zealand, the New Zealand Product Accelerator and Victoria University of Wellington.

\section{Notes}

1. The term exponential is frequently inaccurately misused but in this case it is carefully and deliberately applied.

2. These topics were: settlement, transport, entertainment, shoreline, electricity, sewerage, skyline and buildings. 
3. Surveying and manually modelling each building was an arduous task. Therefore, a computer algorithm was designed which building information could be entered into (number of storeys, window layout, roof type) and a 3D digital model of a single building was output as a result. This process was repeated each time for every building observable in the photographs, resulting in three distinct evolutions of Wellington City.

\section{References}

Griffiths, A. (2008). Shivers down your spine: Cinema, museums and the immersive view. New York: Colombia University Press.

Hein, G. (1998). Learning in the museum. London: Routledge.

Hooper-Greenhill, E. (2000). Museums and the interpretation of visual culture. Routledge, London.

Jenkins, H. (2000). "The work of theory in the age of digital transformation." In R. Stam and T. Miller (Eds.), Film and theory: An anthology. Malden: Blackwell Publishing.

Manovich, L. (2001). The language of new media. Massachusetts: MIT Press.

Maxwell, A. (2000). Colonial photography and exhibitions: Representations of the native and the making of European identities. Leicester University Press.

Marks, L. (2002). Touch: Sensuous theory and multisensory media. Minnesota: University of Minnesota Press.

Opara, E. (2012). "SCAD Museum of Art." Pentagram.com. Retrieved from https://www.pentagram.com/work/scad-museum-of-art/story.

Satyanarayan, A. Moritz, D. Wongsuphasawat, K., \& Heer, J. (2017). "Vega-lite: A grammar of interactive graphics." IEEE Transactions on Visualization and Computer Graphics, 23(1), 341-350.

Segal, A. (2017). "California water rights." Retrieved from https://www.adriensegal. com/california-water-rights.

Tiffin J., \& Rajasingham, L. (1995). In search of the virtual class: Education in an information society. Routledge, London.

Tiffin, H. (1995). "Post-colonial literatures and counter-discourse." In B. Ashcroft, G. Griffiths, \& H. Tiffin (Eds.), The postcolonial studies reader. London: Routledge.

Tufte, E., Hillman Goeler, N., \& Benson, R. (1990). Envisioning information (Vol. 126). Cheshire, CT: Graphics press.

Wright, R. (2008). "Data visualisation." In M. Fuller, (Ed.), Software studies $\backslash$ A lexicon. Massachusetts: MIT Press. 